\title{
The Compound Verb in Munda: An Areal and Typological Overview*
}

\author{
Peter Edwin Hook
}

University of Michigan

\begin{abstract}
A study of six Munda languages shows that the syntactic category compound verb (which alternates with simple verb) may be identified in each one of them. However, while compound verbs in South Munda form systems which closely resemble those found in adjacent Indo-Aryan and Dravidian languages, North and Central Munda feature compound verbs of a very different sort. The South Munda type seems to have arisen as the result of cross-linguistic diffusion from its neighbors while that in North and Central Munda owes its origin to independent developments.
\end{abstract}

The compound verb is one of the syntactico-semantic phenomena common to most South Asian languages regardless of their genetic affiliations (Masica 1976: 141-58). It has been studied in some detail in Indo-Aryan (Pořízka, Hook, Cardona, Zbavitel, etc.) and in Dravidian (Schiffman, Bhat, Annamalai, etc.), but has so far eluded the undivided attention of Austro-Asiaticists.' Even for those languages whose compound verb systems have been analyzed with greater thoroughness the precise definition of the category has been a subject of uncertainty and controversy. ${ }^{2}$ Since I have taken an active part in trying to resolve such controversies vis-à-vis the compound verb in Indo-Aryan, ${ }^{3} \mathrm{I}$ have some reason to hope that I may be able to make a contribution to a horizontal study of the phenomenon within the languages of the Munda family, even if I am not a Mundaist.

The present paper may be divided into four parts. First, using data from Hindi, I give a stipulative definition of the compound verb that I believe to be maximally effective in isolating corresponding constructions in other languages. Second, I apply this definition to data from three South Munda languages (Gta?, Gutob, and Remo). Third, I describe some specific parallels between the South Munda compound verb and that of adjacent Indo-Aryan and Dravidian speech forms. Fourth, I take a brief look at published information on the compound verb in Central Munda (Kharia) and 
North Munda (Santali and Mundari), for it is here-if anywhere-that there is evidence for the compound verb's being indigenous to Munda rather than borrowed from IndoAryan and/or Dravidian.

(I) For the purpose of typological comparison I define the compound verb as a polyverbal sequence composed of a main or 'lexical' verb and one (or sometimes more than one) auxiliary verb such that: (1) they are homophonous with main verbs ${ }^{4}$; and (2) they alternate with their absence. Thus, in:

$\begin{array}{llll}\text { (a) bijəlī } & \bar{a} & \text { gəì } \\ \text { electricity } & \text { come } & \text { WENT }\end{array}$

'The electricity's come on?'

(b) cãlū kər do əb

on do GIVE now

'Put it on now.'

the forms $k \partial r$ and $\bar{a}$ ('do' and 'come') are the main verbs bearing the main semantic load of the verb phrase in each sentence. The forms $d o$ and gəi are the auxiliaries (or, more precisely, the explicators of Masica 1976 or the vectors of Pray 1970 and Hook 1974). These have their homophonous counterparts among the main verbs of Hindi:

$\begin{array}{ll}\text { (c) bijalī gəī } & \\ \text { electricity went } & (g ə \bar{\imath}<j \bar{a} \text { 'go') } \\ \text { 'Electricity's gone?' } & \end{array}$

(d) bil ke paise do, nə?
bill 's money give no (do < de 'give')

'Pay the bill, why don't you?'

By specifying 'homophonous with main verbs' we exclude certain kinds of echoic formations (also very typical and useful in the establishment of the Indian linguistic area: see Emeneau 1956 and 1978):

$\begin{array}{lll}\text { (e) } & \text { səj-dəj } & \text { rahī hogī } \\ \text { spruce-ECHO } & \text {-ing } & \text { be-FUT }\end{array}$

'She must be getting all dressed up.'

By insisting that the auxiliary 'alternate with its absence' we exclude:

(1) sequences of main and modal verb or main verb and tensual auxiliary. Compare (a) and (f) with (g) and (h): 
$\begin{array}{llll}\text { (a) bijəli } & \bar{a} & \text { gəरे? } \\ \text { electricity } & \text { come } & \text { WENT }\end{array}$

'Did the electricity come on?'

(f) bijəlī ār?

electricity come

'Did the electricity come on?'

(g) bijoli $\quad \bar{a} \quad$ sək-egì

electricity come can-FUT

'The electricity may come on.'

(h) bijalī a-egī

electricity come-FUT

'The electricity will come on.'

or with (i) and (j):

(i) bijalī $\bar{a} \quad \operatorname{rah}_{\overline{1}}$ thī

electricity com-ing was

'The electricity was coming on.'

(j) bijəlī āî thì

electricity came was

'The electricity had come on.'

Removing the modal $s o k$ and tensual roh has an easily observable or, better, an easily translatable effect on meaning. Removal of the vector $j \bar{a}$, while affecting the meaning, never does so in a way that would affect the truth value of the utterance as a whole or change an English gloss of it.

(2) Another set excluded by the alternation criterion is that of serial verbs:

(k) papīā le jā-o-ge

papaya take go-2pl-FUT

'Will you take away the papaya?'

The components of a serial verb do not alternate with their absence. Removal of one of them, for instance, of $j \bar{a}$ 'go' in $(\mathrm{k})$, yields an expression whose meaning is very different: 
(l) pəpìtā loge

papaya take-2pl-FUT

'Will you take (eat or buy) papaya?'

If one confines one's attention to a single language such as Hindi, it is possible to find a more interesting definition of the compound verb, one that shows significant parallels in semantic function and syntactic behavior among a large class of polyverbal sequences: a set of invariant unifying properties such as incollocability with negatives (Hook 1974: 98-103); expression of anteriority (Hook 1978b: 149-52), expression of perfective aspect (Pořízka 1972; 543-67; Hook 1987a), inability to express conation (Hook 1974: 163-78). However, as I have shown elsewhere (1982 and 1989), even within Indo-Aryan it is not possible to generalize the relatively rich functional definition of the compound verb that has been developed for Hindi. Therefore, we will examine the compound verb in Munda on the basis of the rather lean (and thus capacious) definition given above.

(II) In the South Munda language Gta?, spoken in Koraput District of Orissa, polyverbal sequences appear with some frequency in the texts available to me. Sequences meeting the definition of the compound verb given above include those formed with auxiliary bi? (homophonous with bi? 'give'), we (homophonous with we 'go') and possibly bo (homophonous with bo 'put; keep'). Thus, bi? in (m):

(m) gte-la hun-dae akaen samwa bason bi?-ke ${ }^{7}$ then child-3pl this story say GIVE-PST

'Then their child told this story.'

(MZ 2:23)

is homophonous with main verb bi? in (n):

(n) gro-gco ke samplae nae-nḍre-hin bi?-e officer to present our-people-pl give-FUT

'Our people will give presents to the officers.'

Furthermore, these auxiliaries alternate with their absence:

(o) b?ba-rae bason-ke

$(\mathrm{MZ} \mathrm{2:22)}$ (cf sentence $\mathrm{m})$

father-3pl say-PST

'Their father said...'

(p) knwe?-rae gwe? we-ge

wife-3pl die GO-RPST

(MZ 2:4)

'His wife had died.' 
(q) nae remwa to gwe?-ge $\quad$ (MZ 10:25) (cf sentence p)
our men indeed die-RPST
'Our men indeed had died.'

In Gta?, as in Hindi-Urdu (sce example k) and some other South Asian languages, sequences of main verbs can be formally indistinguishable from sequences of main verb plus auxiliary: se? pia? 'break by tearing; rip' or jog tlak 'pick up and throw' versus gwe? we 'die-GO; die'. According to Mahapatra (1976: 818-22) these functionally different classes of verb sequences can be identified by their behavior with respect to Gta?'s rule of echo formation. If both verbs in sequence are main verbs, either one (independently of the other) can assume an echoic form:

(r) jog tlak > jog tlik, jag tlak, jig tlik, jig tlak 'pick up (something) and throw (it somewhere)'

However, if the second verb in a sequence is a compound verb auxiliary then an echoic cannot be made from it: ${ }^{8}$

(s) gwe? we $>$ ga? we but *gwe? a, *ga? a

die GO > echoic 'die' (of inferior beings ${ }^{9}$ )

Gutob or Gadaba, another South Munda language spoken in Koraput District in Orissa, has a system which in broad outline resembles Gta?'s. Auxiliaries homophonous with main verbs include ber (cognate with Gta? be?) GIVE:

(t) uson gol-gol-te nom bobrig-o? berr-o? today smoothly you make-enter-PST GIVE-PST ${ }^{10}$ (DOT 19:6) 'Today you put it in smoothly.' (ber as CV auxiliary)

(u) ḍabu be?-to-nom ki dio? loẹi-to-nom (DOT 14:4) money give-HAB-2sg or free diddle-HAB-2sg 'Do you pay or get it for free?' (ber as main verb) and $u i \mathrm{GO}$ :

(v) gol-gol-te gai-gi ui-to (DOT 20:17) smoothly enter-PST GO-HAB 'Smoothly (it) goes in...' (ui as CV auxiliary) 
(w) aspatal-bo? ui-gi-nin du-gu (DOT 15:14)
hospital-to go-PST-1sg be-PST
'I had gone to the hospital.' (ui as main verb)

Auxiliary $u i$ can be shown to alternate with its absence:

(x) soḷi gai-gi ki ura? (DOT 14:20)

thing enter-PST or not

'Did it go in? or not?' (absence of $u i$; $\mathrm{cf}(\mathrm{v})$ )

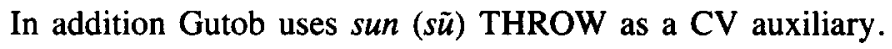

(y) dio? loẹi sun-to-nin

gratis diddle THROW-HAB-1sg

(DOT 14:6)

'I get it free.'

(z) bãḍ gui-ḍa? sũ-o?-nom ki ito du-to

(DOT 17:18)

thing wash-water THROW-PST-2sg or so stay-HAB

'Did you wash it or (just let it) stay like that?'

In his studies of the (South Munda) Remo verb Fernandez (1967: 35-41; 1983: 28-9) lists a cognate form sun 'throw' as an 'intensifier' in 'complex roots' such as bulo sun 'boil over' beside its use as the main verbal element in $i k$-tan sun 'throw away cow-dung'. Other complex roots are formed from wiy 'go' (bana wiy 'forget') and iy 'return' (goy iy 'die'). Use of bed 'give' in Remo appears to be restricted to serial verb sequences (1983:29).

We may unhestitatingly conclude from these data that South Munda does indeed have a compound verb that satisfies the definition presented in (I). Let us now examine some of the properties of the South Munda compound verb in its areal context.

(III) The compound verb in South Mundan does not seem to crop up as often as it does in a Hindi text of the same length. In the Gta? texts available to me, I was able to find no more than thirty instances of it out of more than 500 'opportunities' (i.e. about 5\%). In a text from Juray, another South Munda language, there appear not to be any instances of it at all (Zide 1983). This contrasts with a frequency in Hindi (dialogue) in the neighborhood of $15 \%$. (Such figures must remain approximate since there is a wide degree of indeterminacy in establishing just what constitutes an 'opportunity'. See Hook 1988 and 1989 for detailed figures and discussion.) A quantitative difference of this size implies a qualitative difference of some importance in the functional role of the construction in Hindi and Gta?. In fact, there appear to be some 'gaps' in the Gta? system: No auxiliary plays the role played by le (homophonous 
with 'take') in Hindi. The kind of reflexive or "ingestive" (see Masica 1976: 48) verb that typically prefers le Hindi is simply not found in a compound form in Gta?: con 'eat'; salia? 'ask for'; etc. The one exception appears with bi?:

(aa) taen bha?-ke gsu? c?cwi bi?-la mae gwe? we-ge
that head-to dog smell GIVE-when he die GO-RPST
'When a dog sniffed the head he died.' (MZ 6:25)

(Here, in Hindi, we would expect sügh liyā 'sniff TOOK'.)

The appearance of we GO, too, seems to be restricted. In Mahapatra-Zide it occurs only with gwe 'die' $(2: 4 ; 3: 16 ; 4: 15,26,30)$, tar 'come out, emerge' $(1: 13,14 ; 2: 10$, 17) and $g a$ 'enter' $(8: 2,14)$. In the entire collection it occurs not even once with the verb 'become', while Hindi-Urdu ho jā 'become GO' alone accounts for about one in six compound forms in dialogue." In this the Gta? system resembles that of Marathi where compound forms of transitive verbs occur relatively more freely than do those of intransitives (see appendices in Hook, 1991).

However, on other counts the divergences of the Gta? system from that of HindiUrdu can be explained most easily be comparing it with that of Oriya, the IndoAryan language of the surrounding population. One of the features which distinguish the compound verb system of Oriya from those of other Indic languages is the infrequent use as auxiliary of $n e b \bar{a}$ (equivalent to Hindi's lena TAKE). Ingestive verbs in Oriya take debā GIVE rather than TAKE: $p i$ deba 'to drink' (cf. Hindi $p \bar{\imath}$ lenāa) and khāi nebā 'to eat' (cf. Hindi khā lenā). The expected pi nebā and khāi $n e b \bar{a}$ struck a native speaker (from Puri) as being North Orissan or Bengalicized. The same is largely true of sensory verbs: dekhi debā 'to see', suni jibā 'to hear' (where $j i b \bar{a}$ is homophonous with 'to go'), etc. For other verhs where the Hindi-knower would expect TAKE there simply is no compound form: for nebā 'to take', no *nei $n e b \bar{a})$.

Another peculiarity distinguishing both Gta? and Remo (as well as Oriya and Marathi) from Hindi is the ability of their compound forms to occur as conjunctive participles:

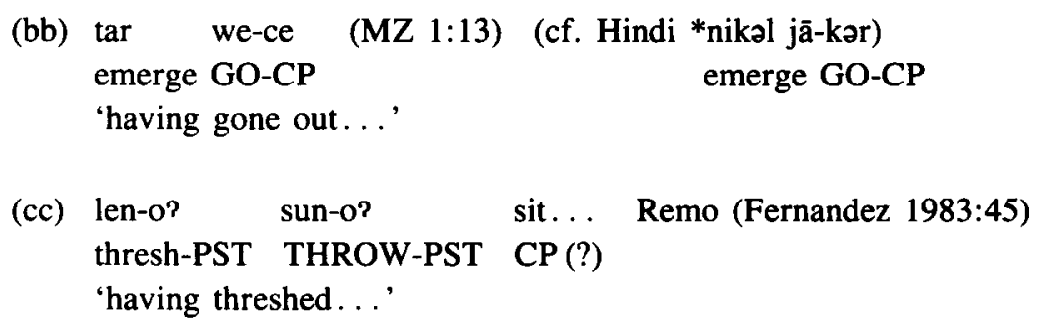


(dd) hli?-ke cu bi?-ce wig-ke (MZ 7:12)
bamboo-to smear GIVE-CP return-PST
'Having smeared (it) on the bamboo they came on home.'
(cf. Hindi *lagā de-kər)
apply GIVE-CP
(ee) bhoji khā-i de-i cāli-golā Oriya dinner eat-CP GIVE-CP went-away
'Having eaten dinner he left.' (cf. Hindi *khā de/le kər) eat GIVE/TAKE CP

The corresponding Hindi forms can only be nikal-kar, loga $-k a r, k h \bar{a}-k a r$, etc. Elsewhere (Hook 1988), I have shown that the compound verb's ability to occur in different syntactic environments has an inverse correlation with the degrees to which vectors are semantically bleached in different languages and with their overall frequency.

The compound verb systems of Gutob and of Remo are to be distinguished from that of Hindi by the prevalence of an auxiliary homophonous with the verb for 'throw': sun or $s \tilde{u}$. It is as frequent as auxiliary ber GIVE; whereas $d \bar{a} l$, its equivalent in Hindi, is much less frequent and semantically more marked than Hindi de GIVE. In this Gutob and Remo seem to have undergone the influence of neighboring Dravidian languages. In fact, two of them Parji (Burrow and Bhattacharya 1963:44) and Ollari (Bhattacharya 1956:47) have the same threefold choice of auxiliaries as Gutob: GIVE, GO, and THROW, with THROW in both Parji and Ollari the most important of the three.

Of course, as persuasive as data of this sort are, we cannot usually be as confident of the direction of influence as we can be of the fact of influence. Indeed, were the compound verb in all of Munda to have the characteristics that we find for it in Gta? and Gutob, it would not be possible to say whether it came into Munda from IndoAryan and Dravidian or vice versa. However, in North Munda and Central Munda (Kharia) there are compound verb systems unlike the ones encountered in Indo-Aryan, Dravidian or South Munda. Because of the isolation and divergence of these systems it is probable that they represent a compound verb proper to Munda, if not to AustroAsiatic in general.

(IV) In his study of South Asia as a linguistic area Masica shows that a construction which appears to meet my definition of the compound verb exists not only in IndoAryan and Dravidian but also (inter alia) in Tajiki, Altaic and (if they are to be considered different from Altaic) Mongolian and Korean. Although he states that the compound verb exists in Munda (Masica 1976:144), he provides no examples or 
evidence except for a table on p. 147 where two unusual items are listed as compound verb-forming auxiliaries in Santali: jom (as a main verb, 'eat') and got? (as a main verb, 'pluck'). These items are sui generis: they appear nowhere else on Masica's chart, and, oddly enough, none of the common (or, for that matter, uncommon) items found in the other languages are to be found in Santali.

Examples of these auxiliaries are available from the excellent dictionaries of Santali and Mundari compiled by Bodding and Hoffman. First, examples of Santali got?:

(ff) malhan god-me (Bodding 2:475)

beans pluck-IMPER ( $g o t$ ? as main verb)

'Pick some beans.'

(gg) hec got?-en-a-c

come PLUCK-PST-IND-3sg

(Bodding 2:475)

'He came quickly/suddenly.'

(hh) ol god-me

write PLUCK-IMPER

(Bodding 2:475)

'Write quickly!'

(ii) nel got?-ked-c-a-n

(Bodding 2:475)

see PLUCK-PST-3sg-IND-1sg

'I had a glimpse of him.'

A similar example from Mundari:

(ji) hukum namjante hiju god-me (Hoffman 5:1470) order on-getting come PLUCK-IMPER

'Come as soon as you get the order.'

A cognate form god 'pluck'12 is used as an auxiliary in the Central Munda language Kharia:

$$
\begin{aligned}
& \text { (kk) in ina? alsi ob-sid god-si?-d-in } \\
& \text { I my axe CAUS-lose PLUCK-have-1sg } \\
& \text { 'I have lost my axe.' }
\end{aligned}
$$

(Pinnow 1965:39)

There is a second auxiliary in Santali with a function similar to that of got? and homophonous with a main verb in the same semantic field. This is hot? which as a main verb has the meaning of 'strip': 
(Il) chĩțkĩriic? hod-me

(Bodding 3:152)

switch strip-IMPER

'Strip the stick (of leaves).'

As a compound verb auxiliary hod expresses speed or vehemence of the action expressed by the main verb:

$$
\begin{gathered}
\text { (mm) lai hod-me } \\
\text { tell STRIP-IMPER } \\
\text { 'Tell (it) quickly.' }
\end{gathered}
$$

The other anomalous item in Masica's chart, namely, jom EAT, is found in Mundari (nn) and Ho (oo):

(nn) en horoko lel jom-me
those people see EAT-IMPER

(Hoffman 7:2098)

'Take a look at those people.'

$$
\begin{aligned}
& \text { (oo) umbul-re dub jom-pe } \\
& \text { shade-in sit EAT-IMPER } \\
& \text { 'Sit (at ease) in the shade.' }
\end{aligned}
$$

(Burrows 1915:89)

This auxiliary is reported to mean 'well', to one's advantage' (Deeney 1975:67-71) and 'for one's benefit or comfort' (Hoffman 7:2098). In this jom seems to parallel (at least in part) the connotations of Hindi's le TAKE (while got? PLUCK and hot? STRIP parallel Hindi's dâl THROW).

Every one of the twelve auxiliaries (GO, COME, RISE, etc.) in Masica's table of "chief explicator auxiliaries" (p. 46) is found thoroughly mixed and scattered among languages of both the Indo-Aryan and Dravidian families and every one of the languages examined has at least 6 members of the set of 12 (except for Sinhalese which has only 3 ). The evidence for linguistic convergence here is overwhelming but the mixing has been thorough enough to make the quest for origins or direction of influence very difficult if not impossible. North and Central Munda which: (1) have auxiliaries found nowhere else and which; (2) seem not to have any of the auxiliaries found everywhere else differ sharply from South Mundan languages like Gta?, Remo and Gutob which look to be completely South Asian in their compound verb systems. This means that if there was a compound verb system in Proto-Munda it must have resembled those of North Munda and Kharia. Secondly, the fact that N. Munda and Kharia do not share any auxiliaries with the rest of South Asia (yet even so have developed a compound verb system) makes the possibility of separate (but parallel) 
origins and development of compound verb systems in Indo-Aryan and Dravidian seem stronger (Hook 1977, Herring ms.)

\section{NOTES}

* An earlier version of this paper was presented at the Second International Conference on Austroasiatic Linguistics (SICAL) under the title: "The Compound Verb in South Munda: A Typological and Areal Sketch." Since then, I have been able to expand its scope and the information on which it is based to include an examination of the compound verb in North and Central Munda as well. I am indebted to Norman Zide who suggested I undertake this study, who invited me to SICAL, and who gave unstintingly of his time and attention in helping me interpret some of the unpublished Munda texts that are at his disposal (DOT and MZ).

1. Which is not to say they have ignored it completely. Most descriptions of whole languages (Deeney, Burrows, Aze, Biligiri, etc.) have a paragraph or two devoted to it. But no one to my knowledge has attempted to make a comparative study before now for all of Munda.

2. An idea of the degree to which descriptions of Hindi disagree on the definition can be had from the chart in Hook 1974:19-20.

3. Hook 1974, 1977, 1978b, 1988, 1989.

4. I do not exclude situations where the main verb can be found only in some other, cognate language.

5. Glosses in capitals (GO, GIVE, THROW, etc.) refer not to the meanings of the auxiliaries themselves but to the meanings of the main verbs with which they are homophonous.

6. Abbreviations are to be interpreted as follows:

CAUS .............. causative affix INTR ........... intransitive CP...........conjunctive participle $\mathrm{MZ} \ldots \ldots$. Mahapatra and Zide texts DOT ......... DeArmonde oral texts $\mathrm{pl} \ldots \ldots \ldots \ldots \ldots \ldots \ldots$ plural ECHO ......... echoic formation PST ............. past tense ERG ............... ergative RPST ............ recent past FUT $\ldots \ldots \ldots \ldots \ldots$ future tense $\mathbf{s g} \ldots \ldots \ldots \ldots \ldots \ldots \ldots$ singular HAB............ habitual aspect TR ............... transitive IMPER .......... imperative $\operatorname{mood}$ first person IND ........... indicative $\operatorname{mood} 3 \ldots \ldots \ldots \ldots$ third person

7. In the Munda transcriptions < ae > represents the front low vowel. In general I have tried to normalize cited data to one uniform transcription wherever possible.

8. Although he does not say so it seems from one of Mahapatra's examples that the compound verb auxiliary can apply to the base plus echo as a whole: gwe? ga? we 'die, etc.' 
9. According to Mahapatra and to Zide (1976), Gta? echoics differ in meaning from the more widespread South Asian formations which Mahapatra (1976) refers to as 'tags'. These are formed by changing an initial consonant (or syllable) and generally express and approximation to or variation on the meaning of the base (for example, Hindi-Urdu kapre wapre 'clothing and what-not', jal šl gayā 'burned up, etc.'). Thus, the replacement of a base vowel with $a$ expresses some inferiority in the subject; with $i$, its small size, etc.

10. Notice that ber GIVE in this example is preceded by the past tense form of the main verb whereas sun THROW in (y) is not. In Remo we find similar variation (from Fernandez 1983):

(a) bana wiy 'forget' vs ajur-o? wiy 'leap over'

(b) gwisun sun 'wash feet' vs len-o? sun 'thresh'

(c) gay sun 'enter' vs bad-or sun 'slap'

Perhaps the variation has a phonological condition with $-o$ ? appearing after all consonantal bases except those in engma. The use in compound verbs of a finite form of the main verb followed by a tinite form of the auxiliary is found in some incipient systems such as that of Baluchi and some dialects of Tajiki spoken in Uzbekistan (Rastorgueva 1964: 101-2).

11. As Norman Zide has pointed out (personal communication) this restriction in Gta? cannot reflect Oriya in which the compound form of 'become' (he-i jā) is fairly common.

12. In his discussion of god in Kharia, Biligiri (1965:47) objects to taking auxiliary god as related to main verb god 'pluck' for the reason that main verb god must always take the transitive set of verb endings whereas the endings used with auxiliary god are transitive or intransitive as the main verb preceding god is transitive or not. Thus

(a) gitag-god-ki sleep-PLUCK-PST (INTR)

'He went to sleep.' (b) gil-got-?og beat-PLUCK-PST (TR) 'He beat (someone) up.'

But this is actually no different from the situation obtaining in Hindi where the compound verb auxiliaries $l e$ and $d e$ homophonous with the transitive verbs TAKE and GIVE exhibit intransitive morphology if the main verbs are intransitive:

(c) mãĩ aj cəl diyã hū

I today go GAVE am

'I've set out today.'

(e) wo mere sāth ho li she me with be TOOK 'She came along with me.' (d) mãĩ ne gāṛi calā dĩ hai I ERG car made-go GAVE is 'I've started the car.'

(f) us ne moze dho liye she ERG socks wash TOOK 'She washed her socks.' 
13. Address correspondence to: Dr P. E. Hook, Program in Linguistics, The University of Michigan, 1076 Frieze Building, Ann Arbor, MI 48109 1285, U.S.A.

\section{REFERENCES}

Annamalai, E.

1979 "Aspects of Aspect in Tamil," International Journal of Dravidian Linguistics 8.

1982 “Dynamics of Verbal Extension in Tamil," International Journal of Dravidian Linguistics 11. 22-166.

Aze, R. R.

1973 "Clause Patterns in Parengi-Gorum," Patterns in Clause, Sentence, and Discourse in Selected Languages of India and Nepal, Part I, R. L. Trail. (ed.), Norman OK: Summer Institute of Linguistics.

Bhat, D. N. S.

1979 "Vectors in Kannada," International Journal of Dravidian Linguistics 8. 300-9.

Bhattacharya, S.

1956 Ollari, a Dravidian Speech, Memoir 3, Calcutta: Government of India Press.

1975 Studies in Comparative Munda Linguistics, Simla: Indian Institute of Advanced Study.

Biligiri, H. S.

1965 Kharia, Poona: Deccan College Postgraduate and Research Institute.

Bodding, P. O.

1929-36 A Santal Dictionary, 5 Vols, Oslo: I Kommisjon Hos Jacob Dybwad.

Burrow, T., and S. Bhattacharya

1953 The Parji Language, a Dravidian Language of Bastar, Herford: Stephen Austin and Sons, Ltd.

Burrows, $\mathbf{L}$.

1915 Ho Grammar, Calcutta: Catholic Orphan Press.

Cardona, George

1977 A Gujarati Reference Grammar, Philadelphia: University of Pennsylvania Press.

Dasgupta, Probal

1977 "The International Grammar of Compound Verbs in Bangla," IL 38. 68-85.

Deeney, J.

1975 Ho Grammar and Vocabulary, Chaibasa: Xavier Ho Publications.

1978 Ho-English Dictionary, Chaibasa: Xavier Ho Publications 
Ekka, Francis

1979 "Some Aspects of Kurux Aspect," International Journal of Dravidian Linguistics 8. 2.

Emeneau, Murray B.

1956 “'India As a Linguistic Area," Language 32. 3-16.

1978 'Review of Masica 1976,' Language 54. 201-10.

Fernandez, Frank

1967 A Grammatical Sketch of Remo: a Munda Language, Unpublished Ph.D. Dissertation, University of North Carolina, Chapel Hill.

1983 "'The Morphology of the Remo (Bonda) Verbs,'" International Journal of Dravidian Linguistics 12. 15-45.

Grierson, George A. (compiler)

1906 Linguistic Survey of India, Vol. 4, S. Konow, (ed.), Calcutta: Government of India.

Herring, Susan

n.d. "Aspectogenesis in South Dravidian," Paper presented at the Ninth International Conference of Historical Linguistics, Rutgers University, August 1989.

Hoffman, Rev. J.

1950 Encyclopedia Mundarica, 13 Vols, Patna: Superintendent of Government Printing, Bihar.

Hook, Peter E.

1991 "The Emergence of Perfective Aspect in Indo-Aryan Languages," in Grammaticalization pp. 59-89, B. Heine and E. Traugott, (eds), Amsterdam: John Benjamins.

1974 The Compound Verb in Hindi, Ann Arbor: Center for South \& Southeast Asian Studies, University of Michigan.

1977 "The Distribution of the Compound Verb in the Languages of the North India and the Question of Its Origin," International Journal of Dravidian Linguistics 6.2. 336-51.

1978a "Perfecting a Test for The Perfective: Aspectual Parallels in Russian, Lithuanian, Modern Greek, Hindi and Pashto,' in University of Michigan Papers in Linguistics 2. 89-104.

$1978 \mathrm{~b}$ "The Hindi Compound Verb: What It Is and What It Does," in Readings in Hindi-Urdu Linguistics, pp. 129-46, K. S. Singh, (ed.), New Delhi: National Publishing House.

1982 "South Asia As a Semantic Area: Forms, Meanings and Their Connections," in South Asian Review 6. 30-41.

1988 "Paradigmaticization: A Case Study From South Asia," in Proceedings of the Fourteenth Annual Meeting of the Berkeley Linguistics Society, pp. 293-303. 
1989 "Determining Thresholds for the Emergence of Perfective Aspect in IndoAryan languages,"' in Papers from the Twenty-fifth Regional Meeting, pp. 203-12, Chicago: Chicago Linguistics Society.

Jenner, P., L. Thompson and S. Starosta (eds)

1976 Austro-Asiatic Studies, Part II, Honolulu: University Press of Hawaii. Mahapatra, K.

1976 "Echo-formation in Gta?," in Austro-Asiatic Studies, Part II, pp. 815-31, P. Jenner, L. Thompson and S. Starosta (eds), Honolulu: University Press of Hawaii.

Masica, Colin P.

1976 Defining a Linguistic Area: South Asia. Chicago: University of Chicago Press.

Munda, R. D.

1969 "Aspects of the Munda Verb," IL 30. 27-49.

Pinnow, H. J.

1966 "A Comparative Study of The Verb in the Munda Languages," in Studies in Comparative Austro-Asiatic Linguistics, N. H. Zide, (ed.), The Hague: Mouton.

1965 Kharia-texte. Wiesbaden: Otto Harrassowitz.

Porízka, Vincenc

1972 Hindština-Hindì Language Course. Prague: Statni pedagogicki nakladetelstvi.

1967-9 "On The Perfective Verbal Aspect in Hindi," Archīv Orientalni 35. $64-88,208-31 ; 36.233-51 ; 37.19-47,345-64$.

Prabodhachandran Nayar, V. R.

1979 "The Aspectual System in Malayalam" International Journal of Dravidian Linguistics 8. 289-99.

Pray, Bruce

1970 Topics in Hindi-Urdu Grammar. Berkeley: Center for South and Southeast Asian Studies, University of California.

1983 "The Story of Two Girls (excerpt from a Juray text)," International Journal of Dravidian Linguistics 12. 112-25.

Zide, Norman $\mathrm{H}$.

1969 "Munda and Non-Munda Austroasiatic Languages," in Current Trends in Linguistics, Vol. 5, pp. 411-30, T. A. Sebeok, (ed.), The Hague: Mouton.

1976 "A Note On Gta? Echo Forms, in Austro-Asiatic Studies, Part II, pp. 1335-43, P. Jenner, L. Thompson, and S. Starosta, (eds), Honolulu: University Press of Hawaii. 